\title{
A CONTRIBUIÇÃO DOS PROCESSOS FORMATIVOS NA COMPREENSÃO DAS DORES EMOCIONAIS DE DOCENTES UNIVERSITÁRIOS
}

\author{
LA CONTRIBUCIÓN DE LOS PROCESOS FORMATIVOS EN LA \\ COMPRENSIÓN DE LOS DOLORES EMOCIONALES DE LOS PROFESORES \\ UNIVERSITARIOS
}

\author{
THE CONTRIBUTION OF TRAINING PROCESSES IN UNDERSTANDING \\ UNIVERSITY PROFESSORS' EMOTIONAL PAINS
}

\author{
Sandra Elisa Réquia SOUZA ${ }^{1}$ \\ Amarildo Luiz TREVISAN ${ }^{2}$
}

\begin{abstract}
RESUMO: Neste texto refletiremos sobre as dores emocionais de docentes universitários e os seus possíveis entrelaçamentos com os processos formativos, pressupondo que eles têm o potencial sinalizador da recuperação da ideia de natureza humana e podem contribuir na reconfiguração dessas dores. O suporte de nossas reflexões procede das investigações neurocientíficas de Antonio Damásio, para quem as relações entre os sentimentos de dor e prazer influenciam o processo cultural humano. Também colabora com o nosso pensamento Baruch Espinosa, cujas ideias alicerçaram as da neurociência de Damásio ao afirmar que os seres humanos afetam uns aos outros e, por meio deste encontro, podem reconhecer-se e aumentar a sua "potência de agir". Para realizar as reflexões aqui propostas recorremos à hermenêutica da tragédia "As Bacantes" de Eurípedes (406 a.C.), cujo potencial metafórico nos auxilia a entender as dificuldades impostas por uma racionalidade proclamada como única possível. Trata-se de uma reflexão teórica que subsidia e sinaliza a pertinência e necessidade de futuras pesquisas envolvendo coleta e análise de dados empíricos, dando vozes aos professores universitários a respeito da questão. As análises reflexivas, evidenciadas neste texto, nos levam a entrever a necessidade de outros saberes docentes que percebam a experiência de uma forma sensível e humanizada, compreendendo aspectos que deverão ir além dos atuais e ampliar a visão acerca da formação profissional. Mesmo diante do detalhamento e abrangência das propostas atuais de categorização dos saberes docentes necessários para a profissionalização, persiste essa carência relativa às dores emocionais docentes.
\end{abstract}

PALAVRAS-CHAVE: Educação. Formação de professores. Dores emocionais. Emoções e sentimentos.

RESUMEN: En este texto reflexionaremos acerca del dolor emocional de los profesores universitarios y sus posibles entrelazamientos con los procesos de formación, suponiendo que tienen el potencial de señalar la recuperación de la idea de la naturaleza humana y pueden contribuir en el proceso de reconfiguración de estos dolores. El apoyo de nuestras reflexiones

\footnotetext{
${ }^{1}$ Universidade Federal de Santa Maria (UFSM), Santa Maria - RS - Brasil. Doutoranda no Programa de PósGraduação em Educação. ORCID: https://orcid.org/0000-0002-5560-0519. E-mail: saereso@gmail.com

${ }^{2}$ Universidade Federal de Santa Maria (UFSM), Santa Maria - RS - Brasil. Professor Titular no Programa de Pós-Graduação em Educação. Pós-Doutor em Humanidades (UC3M) - Espanha. Bolsista de Produtividade em Pesquisa do CNPq - Nível 1C. ORCID: https://orcid.org/0000-0002-3575-4369. E-mail: trevisanamarildo@gmail.com
}

RIAEE - Revista Ibero-Americana de Estudos em Educação, Araraquara, v. 16, n. 2, p. 524-538, abr./jun. 2021. e-ISSN: 1982-5587 
proviene de las investigaciones neurocientíficas de Antonio Damásio, para quien las relaciones entre los sentimientos de dolor y placer influyen en el proceso cultural humano. También colabora con nuestro pensamiento Baruch Espinosa cuyas ideas han respaldado las de la neurociencia de Damásio cuando afirmó que los seres humanos se afectan entre ellos y a través de este encuentro pueden reconocerse y aumentar su "potência de agir". Para llevar a cabo las reflexiones propuestas aquí, recurrimos a la hermenéutica de la tragedia "As Bacantes" de Eurípides (406 a. C.) cuyo potencial metafórico nos ayuda a comprender las dificultades impuestas por una racionalidad proclamada como la única posible. Los análisis reflexivos, evidenciados en este texto, nos llevan a entrever la necesidad de otros saberes docentes que perciban la experiencia de una manera sensible y humanizada, entendiendo aspectos que deberán ir más allá de los actuales y ampliar la visión acerca de la formación profesional. Aún ante la especificación y el alcance de las propuestas actuales para categorización de los saberes docentes necesarios para la profesionalización, persiste esta carencia en relación a los dolores emocionales de los profesores.

PALABRAS CLAVE: Educación. Formación del profesorado. Dolor emocional. Emociones y sentimientos.

ABSTRACT: In this text we will reflect on the emotional pain of university professors and their possible connections with the training processes, presupposing that they have the potential to signal the recovery of the idea of human nature and can contribute to the process of reconfiguring these pains. The support of our reflections comes from Antonio Damásio's neuroscientific investigations to whom the relations between the feelings of pain and pleasure influence the human cultural process. It also collaborates with our thinking Baruch Espinosa whose ideas underpinned those of Damásio's neuroscience when he affirmed that human beings affect each other and through this meeting they can recognize themselves and increase their power to act. In order to carry out the reflections proposed here, we used the hermeneutics of the tragedy "As Bacantes" by Euripides (406 BC) whose metaphorical potential helps us to understand the difficulties imposed by a rationality proclaimed as the only possible one. The reflective analyses, evidenced in this text, lead us to glimpse the need for other teaching knowledge that perceive the experience in a sensitive and humanized way. They contribute to the understanding of aspects that should go beyond the current ones and broaden the vision about professional training. Even in view of the detail and scope of the proposals currents for categorizing the teaching knowledge necessary for professionalization, this shortage regarding the teachers' emotional pain persists.

KEYWORDS: Education. Teacher education. Emotional pain. Emotions and feelings.

\section{Introdução}

Ao desistir da sua autodeterminação, os sujeitos de uma comunidade declinam da capacidade de reflexão e do potencial de realizar movimentos capazes de reconhecer a sua humanidade e tornam-se estranhos a si mesmos. Essa condição é uma relação distorcida dos seus estados internos e o abandono da ideia de um elo afetivo, consigo próprio e com os outros. Ao atender às condições estranhas a si, legitima determinações externas, nem sempre 
condizentes com a sua humanização. Essa é uma das razões principais das suas dores e sofrimentos. As dores emocionais dos professores universitários acenam para esta realidade e elas se inscrevem ou acontecem concomitantes à crescente codificação e racionalização do seu trabalho. Condições essas impostas pelas prescrições ministeriais, pautadas na mercantilização da educação e reproduzidas no imaginário docente, culminando numa ação pedagógica orientada para a simples informação e reprodução de uma sociedade em sofrimento.

As orientações curriculares, pedagógicas e avaliativas se apresentam, na maioria das vezes, como a única forma de proceder diante dos discentes, impossibilitando, aos docentes, visualizar outra lógica de atuação. A dedicação à informação e à disciplinarização do conhecimento, em detrimento da experiência, provoca a intenção alheia e escusa de retirar os sujeitos das pautas de discussões da atualidade. Atendendo a este tipo de demanda, a profissão atravessa a fronteira da "vocação" para uma perspectiva sociopolítica que se iniciou na década de 1970. Travessia necessária, mas que culminou numa espécie de legitimação de ideologias contrárias ao sentido do humano, atendendo a determinações da indústria cultural e minimizando a grandiosidade do agir pedagógico e da formação concernente às questões humanizadoras.

Os programas formativos de professores universitários seguem os preceitos dessa lógica perversa de mercantilização das relações, reificando pessoas, pois que não ampliam seu sentido para além da normatividade técnico-científica. E o agir pedagógico universitário aliase a essa racionalidade alheia à humanidade dos sujeitos do processo formativo. Ele nega as situações necessárias e provocativas de vínculos subjetivos e intersubjetivos ao não reconhecer as articulações entre razão, emoção e sentimentos e pelas dificuldades em compreender demandas constitutivas das ações pedagógicas: as emocionais e sentimentais.

Neste sentido, buscamos na tragédia “As Bacantes” de Eurípedes (406 a.C.) o potencial metafórico para o nosso estudo, pois ela evidencia, dentre outras coisas, as dores daquele que permaneceu fiel a uma racionalidade proclamada pelo poder da cidade, ignorou e combateu a natureza humana por não ser capaz desse reconhecimento. Essa via de compreensão nos auxilia a entender as dores emocionais pela negação da subjetividade instaurada pelo paradigma da representação. Já para as mulheres tebanas (bacantes) não houve dificuldades em reconhecer as suas emoções e sentimentos. Elas naturalmente assumiram o culto dionisíaco anunciador de outra forma de se portar diante de si mesmas, do outro e da vida. 
As Bacantes, de Eurípides, narram a história de Dioniso de acordo com o mito grego de adesão ao deus: Dioniso é filho de Zeus e da princesa tebana Sêmele, filha de Cadmo. As irmãs de Sêmele não creem na divindade do sobrinho e, dessa forma, a família real tebana não reconhece Dioniso como deus e maldiz os cultos dionisíacos. Dionísio planeja uma vingança contra a família real tebana, pois necessita comprovar a sua divindade e estabelecer os ritos dionisíacos em Tebas. Para cumprir tais propósitos, Dioniso, de acordo com a sua phýsis, enlouquece todas as mulheres tebanas, que abandonam as tarefas domésticas e transformamse em bacantes, ou seja, em adoradoras de Baco (Dionísio). Diante de tal desordem social, o rei Penteu, herói trágico, declara guerra contra Dioniso, e planeja evitar a propagação dos cultos dionisíacos em Tebas. É a partir desse ponto que se inicia o conflito trágico: Penteu tentará lutar contra o semideus, e Dioniso punirá o rei pelos ultrajes sofridos. Penteu é morto pelas bacantes e sua cabeça é levada a Tebas e oferecida à aristocracia da cidade.

Há um antagonismo curioso nas reações das mulheres tebanas e da aristocracia da época (poder temporal), e ele nos incita os seguintes questionamentos: O que levou as bacantes a reconhecer o culto dionisíaco antes dos outros cidadãos tebanos? Estariam elas preparadas por algum "processo educativo" para essa aceitação e reconhecimento? Por que o Rei Penteu e sua corte não aceitam o novo culto a ponto de sua cabeça ser decepada?

Esses questionamentos são pertinentes na medida em que buscamos compreender os entrelaçamentos possíveis entre as dores emocionais docentes e os processos formativos. $\mathrm{Ou}$ seja, será possível para esses processos sinalizar a recuperação da ideia de natureza humana para habilitar ações na busca da plenitude das relações? A nossa tese indica a contribuição desses processos, em prol da minimização das dores emocionais, no sentido de buscarem ações coerentes com as sensibilidades envolvidas no processo pedagógico. O estudo propõe uma reflexão teórica que subsidia e sinaliza a pertinência e necessidade de futuras pesquisas envolvendo coleta e análise de dados empíricos, dando vozes aos professores universitários a respeito da questão. As análises reflexivas, evidenciadas neste texto, nos levam a entrever a necessidade de outros saberes docentes que percebam a experiência de uma forma sensível e humanizada, compreendendo aspectos que deverão ir além dos atuais e ampliar a visão acerca da formação profissional.

Para compreendermos esses vínculos possíveis, buscamos, num primeiro momento, entender as relações entre os sentimentos de dor e prazer e o processo cultural humano a partir das reflexões de Antonio Damásio ${ }^{3}$. Os processos formativos e pedagógicos são aparatos

${ }^{3}$ Neurocientista português, professor da cátedra David Dornsife de Neurociência, Psicologia e Filosofia, e diretor do Instituto do Cérebro e Criatividade na Universidade do Sul da Califórnia, em Los Angeles. É 
culturais criados a partir de mentes individuais no esforço de sanar as dificuldades oriundas do processo pedagógico. No momento seguinte refletiremos sobre os fatores de adoecimento emocional causadores das dores emocionais docentes, apostando que este entendimento auxiliará no fornecimento de pistas para trilhar o caminho de compreensão da contribuição dos processos formativos no equacionamento dessas dores.

\section{As articulações entre emoções e sentimentos e a cultura}

Para Damásio, (2004, p. 09) a dor e o prazer são ingredientes essenciais dos sentimentos e pouco compreendidos pela nossa cultura. Na sua concepção:

O sentimento de dor ou prazer são os alicerces da mente ou de toda e qualquer qualidade entre dor e prazer, os sentimentos de toda e qualquer emoção, ou dos diversos estados que se relacionam com uma emoção qualquer, são as mais universais das melodias, uma canção que só descansa quando chega o sono, e que se torna um verdadeiro hino quando a alegria nos ocupa, ou se desfaz em lúgubre réquiem quando a tristeza nos invade.

Além da sua presença constante na formação da mente humana, os sentimentos, que perpassam a escala da dor ao prazer, provocam a criação da cultura com seus aparatos relativos às leis, arte, religião, filosofia, educação, ciência e tecnologia, entre outros. Ao mesmo tempo em que auxiliam na criação da mente cultural, eles vão realizando ações relativas à promoção de estratégias e dispositivos comportamentais capazes de assegurar o equilíbrio, a preservação e o florescimento da vida. Dito de outra forma, além de serem os ingredientes essenciais à mente humana, os sentimentos de dor e prazer são partícipes da mente cultural, pois o processo natural de manutenção e regulação da vida orienta o organismo a funcionar dentro dos parâmetros compatíveis com a preservação e florescimento da vida. Nesse processo, os sentimentos atuam de forma central, considerando os vários estágios entre a dor e o prazer.

No caso da dor, Damásio (2017, p. 236) informa que:

neurologista e neurocientista e as suas investigações têm fornecido contributos fundamentais para a compreensão dos processos cerebrais subjacentes às emoções, aos sentimentos e à consciência. Os seus estudos sobre a função do afeto na tomada de decisão têm um forte impacto na neurociência, psicologia e filosofia. Autor de numerosos artigos científicos, foi nomeado Pesquisador Altamente Citado pelo Instituto de Informação Científica e é considerado um dos mais eminentes psicólogos dos nossos tempos. É membro da Academia Nacional de Medicina e da Academia Americana de Artes e Ciências, da Academia Bávara de Ciências e da Academia Europeia de Ciências e Artes. Suas pesquisas indicam a possibilidade de uma nova visão do cérebro e da relação entre mente e corpo, superando a visão reducionista e mecanicista cartesiana. Para ele o cérebro é uma entidade na qual reside a nossa individualidade e nossos mundos emocionais, éticos ou morais, assim como está inscrita nele a própria sociedade e a nossa essência.

RIAEE - Revista Ibero-Americana de Estudos em Educação, Araraquara, v. 16, n. 2, p. 524-538, abr./jun. 2021. e-ISSN: 1982-5587 
Em primeiro lugar, tal como vimos quando os organismos são obrigados a operar fora dos limites do bem-estar e caminham para a doença ou mesmo a morte $[\ldots][\ldots]$ os sentimentos provocam perturbações poderosas que injetam no processo de pensamento a procura da gama homeostática desejável. Em segundo lugar, além de gerarem preocupação e de induzirem ao pensamento e à ação, os sentimentos servem de árbitros da qualidade da resposta.

A dor, neste entendimento, passa a ser um sinalizador na ativação de mecanismos auxiliadores na conquista do equilíbrio homeostático. Na sua participação da mente cultural, os sentimentos atuam como árbitros e negociadores das respostas às necessidades humanas. Eles são árbitros da qualidade dessas respostas. Dessa forma, a articulação entre razão e sentimentos se manifesta também no tratamento e negociação da dor, pois quando ela motiva uma solução, a redução dela é indicada pelo sentimento da dor que se atenua. É o sentimento que decide se o esforço resultou eficaz ou não.

Segundo Damásio (2017), a dor e o sofrimento provocam o processo de imaginação que cria as condições, estrutura, ações e formas de atuação humana na busca pelo seu alívio. Procuramos encontrar formas de contrariar os sentimentos negativos e de preservar nos positivos. Uma das soluções engendradas pela própria natureza diz respeito ao convívio com outros indivíduos, que numa situação de dor exige do outro a empatia e a compaixão por meio de gestos afetuosos e protetivos. O que em geral resulta na reposição homeostática daquele indivíduo que sofre e o leva a outros estados de sentimentos mais complexos, como esperança e gratidão, e a uma elaboração racional desses sentimentos.

Para o neurocientista há uma ponte entre o que ocorre no cérebro e os acontecimentos da vida social, em termos de organização. A vida e a organização social são um reflexo extraordinariamente importante da organização básica afetiva. Assim, há uma correlação intrínseca e benéfica entre a socialidade e os afetos positivos. As situações de dor e sofrimento provocam, no outro, reações inteligentes para a sua amenização e auxiliam no equilíbrio da sua homeostasia.

Para sanar as dores e os sofrimentos, a nossa cultura adota ações e constructos elaborados e acionados, muitas vezes, de forma imediatista. Eles são calculados e previstos para estabelecer a definição e o sentido do prazer e divulgados como a única forma de se alcançar a felicidade. Para amenizar as dores, aprendemos a buscar soluções rápidas e superficiais, sem o investimento de energia necessária para o alcance de uma solução efetiva. E nesse rol de atitudes estão o uso de drogas lícitas e ilícitas, alienação nas religiões, busca desenfreada pela beleza do corpo e status social e profissional, entre outros. E, no entanto, 
todas são paliativas para solucionar um problema complexo e com sinais que indicam a necessidade de mudanças profundas, inclusive na maneira de pensar e sentir.

As ideias colocadas até aqui indicam a necessidade da harmonização dos aspectos racionais com os emocionais, alterações complexas na postura de vida e formas de pensar e valorização das relações de interação e dependência entre as pessoas. E é na interação com o outro que nos constituímos e nos conhecemos a nós mesmos e construímos os constructos sociais necessários para nossa vida.

Espinosa (2019) indica as afecções do corpo como promotoras do aumento ou a diminuição da potência de agir. Para ele, ao afetarmo-nos uns aos outros a "[...] potência de agir é aumentada ou diminuída, estimulada ou refreada, e, ao mesmo tempo, as ideias dessas afecções" (p. 50). O filósofo vai mais além, explicando que "Assim, quando podemos ser a causa adequada de alguma dessas afecções, por afeto compreendo, então, uma ação; caso contrário, uma paixão.” (p. 50). Em outras palavras, os seres humanos afetam uns aos outros e é por meio deste encontro que podem reconhecer-se e aumentar o diminuir a sua potência de agir. O corpo tem o poder de afetar de inúmeras maneiras simultâneas outros corpos e ser, por eles, afetado. Ele se define tanto pelas relações com o seu próprio organismo como com os demais corpos, sendo alimentado e revitalizado enquanto também alimenta e revitaliza. E, neste sentido, a alma é receptora dessas imagens, produzidas por essa trilha dupla e, ao interpretar essas imagens, passa a ter as ideias propriamente ditas. A interiorização da causalidade externa, ora fortalece o conatus, ora o enfraquece, dependendo do sentimento provocado na afecção. Nas palavras do filósofo: "Digo também que por uma afecção ou paixão a alma afirma a força de existir, maior ou menor que antes, do seu corpo ou de uma parte dele.” (ESPINOSA, 2002, p. 280). O que reforça a ideia de que o reconhecimento do individual, bem como as dores e prazeres, também advém dessas afecções.

Para o filósofo, a virtude da alma, e sua força interior, dependerá de sua capacidade para interpretar as imagens de seu corpo e dos corpos exteriores. Assim, passa-se da condição de causa inadequada (paixões) para a causa adequada (ação), na medida em que das ideias inadequadas constrói-se as adequadas. A passagem da passividade para a atividade é um trabalho interpretativo da alma realizado mediante os afetos como possibilidade de descobrirse como causa interna deles. $\mathrm{O}$ indivíduo é causa adequada quando alguma coisa pode ser conhecida clara e distintamente pela sua natureza ${ }^{4}$, e neste sentido ele é ativo. Do contrário o

\footnotetext{
${ }^{4}$ Natureza, para o filósofo, é aquilo que se confunde inteiramente com a ideia de Deus e "da necessidade da natureza divina podem resultar coisas infinitas em número infinito de modos, isto é, tudo o que pode cair sob um intelecto divino" (ESPINOSA, 2002, p. 100). Deus é natureza naturante, pois existe necessariamente e cada RIAEE - Revista Ibero-Americana de Estudos em Educação, Araraquara, v. 16, n. 2, p. 524-538, abr.jun. 2021. e-ISSN: 1982-5587 DOI: https://doi.org/10.21723/riaee.v16i2.13533 
indivíduo é passivo. Assim, para Espinosa, os seres humanos são naturalmente passionais, pois buscam o interesse próprio, mesmo que isso prejudique os outros. O desafio é abandonar essa passividade por meio do esforço e da vontade.

Assim sendo, aos modos da substância divina, os seres humanos interpretam a si mesmos, e as suas afecções são de diferentes formas, de acordo com a sua estrutura psíquica e afetiva, apetites e desejos.

Neste sentido, os afetos são a essência do humano, Deus-Natureza é o indivíduo em si mesmo, e a força de pensar e agir livremente só se dá na companhia de outros. Da mesma forma que nos constituímos no encontro com os outros, também auxiliamos na sua constituição e formamos uma autoimagem nesta interlocução.

Tal como Freud (2009) indicou sobre o comportamento do indivíduo a partir das relações com outros de um grupo social, agimos não como cópia do outro, mas dessas relações surge um "algo mais" em todos os interlocutores do processo. No grupo, os indivíduos são transformados, são colocados em uma espécie de mente coletiva que os fazem sentir, pensar e agir de forma diferente daquela sob a qual faria em isolamento. Para o psicanalista, o inconsciente comanda a ação do indivíduo no mundo da vida, ou seja, "Por trás das causas confessas de nossos atos jazem indubitavelmente causas secretas que não confessamos, mas por detrás dessas causas secretas existem muitas outras, mais secretas, ainda, ignoradas por nós próprios". (FREUD, 2009, p. 19). Neste sentido, o "Eu real" é mascarado pelo "Eu ideal" para evitar a emersão daquilo que está submerso, silenciado e acomodado.

Dessa forma, a segurança é procurada naquilo que é igual, comum, padronizado e, assim, aceitável socialmente. A máscara do "Eu ideal” é aquela utilizada pelo coro na tragédia d'As Bacantes, pois ela esconde o diferente, o singular, a essência. Há uma intencionalidade no seu uso. Ela representa a disciplina, as aparências, as atitudes e os discursos préestabelecidos num movimento de legitimação do status quo. De toda forma, a máscara indica os esforços em se manter os conteúdos inconscientes submersos, pelo medo de admiti-los como parte integrante do self e, também da não aceitação dos outros. Ela esconde as

coisa do mundo existe a seu modo e é uma manifestação divina. Deus se basta a si mesmo num processo de auto manifestação contínua.

${ }^{5}$ Para Damásio "eu" ou o self é continuamente ativado pelas representações de acontecimentos da nossa autobiografia de onde é possível reconstituir a noção de identidade a partir da ativação parcial de mapas sensoriais dotados de organizações topográficas. Ele é também ativado pelas representações primordiais do nosso corpo que se constitui em peça-chave para a construção da imagem do corpo e para a noção de "eu" e da nossa "subjetividade". Sempre que nos reportamos ao self nós nos reportamos à ideia de identidade e ao conjunto de características que definem um indivíduo. 
diferenças no homogêneo, buscando uma segurança ilusória. Mas os conteúdos inconscientes estão latentes, comandam e direcionam o agir humano.

Para Espinosa, a alma fabrica causas imaginárias daquilo que se passa em si mesma, no seu corpo e em tudo que a rodeia, envolvendo-se em um emaranhado de explicações ilusórias. Para o filósofo, são explicações parciais frutos da ignorância das causas adequadas. Isso não significa que a alma esteja impedida do conhecimento verdadeiro, o bloqueio à verdade é imposto por ela mesma, pois deixa a iniciativa do conhecimento ao corpo, capaz somente de imaginar. Ao assumir a sua natureza pensante, a alma assume a sua potência de pensar, possibilitando o conhecimento.

Para o filósofo seiscentista, o homem é livre não no sentido de ter livre-arbítrio e escolher entre alternativas possíveis, mas por ser uma parte da natureza divina, ou seja, dotado de força interior para pensar e agir por si mesmo. A felicidade pode ser alcançada por meio deste esforço em fundir a alma no absoluto divino que é perfeito desde sempre. A alma não está impedida de ser livre, mas a sua liberdade será alcançada na medida do seu esforço em libertar-se. A liberdade de pensamento, de expressão e de ação espinosiana acena para o declínio do imaginativo e do ilusório, impostos pelos poderes estabelecidos, na busca da saída da servidão.

O esforço pela liberdade espinosiana está implícito na ideia de melhoria da homeostasia de Damásio e dependente de uma educação em massa no sentido de coletivizar a ação humana para viver em harmonia com o outro e consigo mesmo. Para Damásio (2017), os sentimentos ainda não receberam o status merecido como motivadores e negociadores da grande empresa cultural humana e a dor foi, e ainda é, um dos impulsionadores do desenvolvimento científico e tecnológico, bem como o desejo, os anseios, a ganância, entre outros sentimentos.

Para ele (idem), os sentimentos de dor e prazer são alicerces da mente e não nos damos conta disso, pois estamos com a nossa atenção voltada para as ilusões, acontecimentos e objetos do mundo, bem como com as imagens de palavras e frases que os descrevem. Tratamos as nossas dores com amenizadores temporários a fim de alcançarmos o bem-estar, por não compreendermos a nós mesmos e por não fazer ideia da função dos sentimentos sob o ponto de vista biológico (DAMÁSIO, 2017, p. 12).

A construção de um projeto de educação para o desenvolvimento de atitudes afetivas tem obstáculos a enfrentar, considerando as dificuldades em se romper com algumas determinações externas. Damásio (2017, p. 307) aponta para um projeto educativo que: 
[...] tenha como objetivo criar ambientes saudáveis e socialmente produtivos, terá de destacar comportamentos éticos e cívicos e de encorajar as virtudes morais clássicas - honestidade, bondade, empatia e compaixão, gratidão e modéstia. Deverá ainda abordar valores humanos que transcendam a gestão das necessidades imediatas da vida.

Para o neurocientista, esse projeto educativo, necessariamente, é um projeto de longo prazo, pois a perfeição homeostática alcançada no estágio homeostático mais básico levou milhares de milhões de anos de evolução. Se essa evolução levou tanto tempo para aperfeiçoar as suas operações, a condição humana atual não tem como harmonizar as necessidades homeostáticas de tantos e diversos grupos culturais em pouco tempo. Mas, ele reconhece que ainda não persistimos de forma consistente e abrangente para a sua construção.

As dores emocionais acenam para a urgência da criação de condições minimizadoras de suas causas. Elas mobilizam repensar os aparatos culturais que, por algum motivo, foram criados para dissimular as suas reais origens. Talvez devamos refletir sobre a sabedoria das mulheres de Tebas ao aceitar sem dificuldades o "novo" culto, como ponto de partida para repensar a nossa atuação no mundo.

\section{Fatores de adoecimento emocional docente}

As pesquisas recentes sobre o mal estar docente indicam uma multiplicidade de fatores provocadores das dores emocionais de professores. As variadas situações que afetam docentes em seus aspectos pessoais e profissionais e causadoras do "mal estar docente" relacionam a valorização profissional, gestão do tempo, desgastes e conflitos na relação pedagógica com alunos e colegas da profissão, os desafios da adolescência $^{6}$ e da juventude ${ }^{7}$, expectativas futuras, inseguranças e fragilidade diante das vivências traumáticas, tragédias e violências cotidianas, conflitos e traumas, entre outros.

Muitos desses fatores são aspectos externos determinando e motivando uma movimentação interna e, na maioria das vezes, acionam uma atuação em direção à racionalização de tais impasses. Essa opção mostra as dificuldades para se realizar uma movimentação interna no sentido de sublimar as relações e buscar dentro de si as respostas para as tribulações conflituosas.

Ao se deparar com as questões que fogem dos elementos fornecidos na sua formação profissional, entram em colapso as certezas e as seguranças conquistadas durante a formação

\footnotetext{
${ }^{6}$ Estatuto da Criança e do Adolescente - Lei 8069/90 | Lei no 8.069, de 13 de julho de 1990. Art. $2^{\circ}$
}

${ }^{7}$ Estatuto da Juventude. Lei n. 12.852, de 5 de agosto de 2013 . Art. $1^{\circ} \S 1^{\circ}$ 
inicial. Como na dor física, se procura a automedicação ou, no máximo, alguém conhecido que entenda um pouco mais da situação em decurso; o professor busca sanar as suas dificuldades com as próprias ferramentas disponibilizadas por uma formação profissional que recorre apenas ao tratamento racional das questões pedagógicas.

Com o objetivo de amenizar essas e outras situações foram se estabelecendo processos formativos, de acordo com cada época, e paradigmas norteadores da ciência e da educação, buscando elencar temas e metodologias que dessem conta das demandas que se apresentavam.

Para Berheins (2007, p. 441), “Os paradigmas determinam as concepções que os professores apresentam sobre a visão de mundo, de sociedade, de homem e da própria prática pedagógica que desenvolvem em sala de aula". Isto significa a determinação de critérios paradigmáticos na educação e na formação de professores, e esses critérios priorizam a fragmentação, especialização e supervalorização do conteúdo e da técnica, a neutralidade de um conhecimento alcançável por meio de uma razão pura, entre outros. Eles demarcam as situações, os programas, as metodologias dos processos formativos e se organizam em torno do distanciamento entre teoria e prática e na ênfase da reprodução do conhecimento. Em consequência, a prática pedagógica é encaminhada como o saber-fazer, e a predominância do domínio do conteúdo, com metodologia de transmissão de conhecimentos específicos da área de atuação e conteúdos culturais. Para tanto, a concepção do "ser professor" é ser especialista na sua área de formação e, portanto, dominar conhecimentos científicos, conceitos e estrutura disciplinar, legitimando a racionalização, a fragmentação e a visão linear, pautadas no cartesianismo.

Precisamos considerar que o sujeito preconizado pelo paradigma da representação tornou-se infeliz, distante da sua humanidade e predador da natureza. Nessa perspectiva, Biesta (2013) indica a "morte do sujeito". Ou seja, o projeto moderno de um sujeito autônomo capaz de gerar conhecimento racional, de exercer ações individuais para o progresso chegou às últimas consequências e, articulado com o projeto neoliberal, aciona, no inconsciente, as formas legitimadoras das ações deste último.

$\mathrm{Na}$ educação superior, as tentativas de solução para a crise do sujeito e da sociedade giram em torno de discussões em direção à profissionalização docente e à ação pedagógica (Mazetto (2012), Cunha (2007a; 2007b), Pimenta e Anastasiou (2002), Pimenta (2005), Tardif (2012), Tardif e Raymond (2000), entre outros); como uma forma de resistência aos impasses do desprestígio profissional e o objetivo de alavancar a pedagogia universitária. Os discursos sobre os processos formativos e prática pedagógica fazem a crítica às questões paradigmáticas que atravessam os seus elementos, mas ainda têm dificuldades em se 
desvincular totalmente do paradigma que permeia essas questões e relações. Nos seus esforços realizam a crítica necessária, mas insuficiente, por fazê-las por dentro dele.

Para além dessas dificuldades, Cunha (2007a, p. 13) alerta para a apropriação e reconstrução do discurso por uma educação emancipadora, pela lógica liberal-mercadológica, “[...] usando processos de participação, aplicou os princípios de gerência empresarial na manutenção/aumento da produtividade, fazendo com que o discurso da profissionalização fosse presa fácil de uma visão neotecnicista".

Para a pesquisadora, a compreensão e a crítica que vêm sendo propostas, sozinhas, não bastam para avançar. É preciso algo mais. Segundo ela:

\begin{abstract}
Mesmo o significativo acúmulo de experiências e investigação sobre o tema parece ainda insuficiente para construir indicadores com alguma segurança sobre a base epistemológica da profissão. Volta-se hoje a procurar algo mais que, em não sendo puramente intuitivo, não descarte formas sensitivas de construção da docência. (CUNHA, 2007b, p. 13)
\end{abstract}

A autora indica a necessidade de se pensar em uma base epistemológica da profissão que vá além dos aspectos da prática e tenha uma abrangência maior, contemplando os variados aspectos da ação pedagógica. A epistemologia da prática indica que nela o professor deixaria de ser um mero reprodutor mecânico, tornando-se um agente de busca de soluções para os seus impasses. Essa ideia se pauta na visão de que a docência deve se caracterizar por um pensamento que interpreta, compara, analisa e diferencia a realidade social e educativa. Sendo assim, a valoração da prática indica que nela se verifica um espaço de construção de saberes.

Por outro lado, há também os que apostam na prática aliada à teoria, sendo a teoria entendida não como uma simples aplicação direta e linear, mas como impulso à reflexão. Neste sentido, sugerem a teoria e a prática mediadas pela cultura e a articulação do presente com o passado, pressupondo, assim, o estímulo para o diálogo e a interpretação. Dessa forma, o trabalho docente passa a requerer a simbiose dessas duas vertentes da profissionalização. Isto significa que teoria e prática são aliadas no trabalho de retroalimentação entre ambas, empoderando a construção dos processos formativos.

Essa premissa faz parte do discurso atual e como ponto de partida para a profissionalização docente, mas tem dificuldades na sua execução, pois os processos formativos ainda se pautam na epistemologia da prática. Eles se configuram em torno de temas como cognição, memória, didática, metodologia, conteúdo, avaliação, tal qual se efetivam em sala de aula. 
Dessa forma, nos aliamos à dúvida de Cunha (2007b, p. 13): Como encontrar esse “algo mais que não seja puramente intuitivo, que não descarte formas sensitivas de construção da docência?” Talvez seja necessário construir paulatinamente uma nova visão de educação e docência, recriando o seu sentido para além dos aspectos da prática. Mesmo a teoria precisa se reinventar e assumir uma nova forma de pensar e romper com o paradigma que esbarra na sua insuficiência em fornecer respostas para as várias questões postas na contemporaneidade.

\section{Considerações finais}

As reflexões propostas acerca das perspectivas que envolvem as relações entre razão, emoção e sentimentos flutuam em todas as direções da condição humana. Essa visão conciliadora do humano tem imbricações com as diversas áreas do conhecimento e diz respeito, também e diretamente, à educação. Ela é oportuna à formação e desenvolvimento de professores universitários, pois é uma possibilidade ontológica que além de esbarrar em um paradigma que persiste em permanecer impondo regras com os seus pressupostos, também é percebida com inseguranças, desconfianças e dúvidas face ao sistema vigente.

As análises reflexivas, evidenciadas neste texto, nos levaram a entrever a necessidade de outros saberes docentes que percebam a experiência de uma forma sensível e humanizada, compreendendo aspectos que deverão ir além dos atuais e ampliar a visão acerca da formação profissional. Mesmo diante do detalhamento e abrangência das propostas de categorização dos saberes docentes necessários para a profissionalização atuais, persiste essa carência relativa às dores emocionais docentes.

Assim, temos dois aspectos a considerar para uma nova configuração dos processos formativos de professores universitários, isto é, pensar sobre esses saberes e, a partir deles, buscar temas, metodologias e estrutura física viabilizadoras de tal realização. O start para as reflexões sobre esses saberes nos encaminha para uma das questões possíveis e contribuidoras para a efetivação da sua constituição de forma que os processos formativos auxiliem na compreensão das dores emocionais de docentes universitários. Esse questionamento gira em torno da autocompreensão dos professores universitários sobre as suas dores emocionais, isto é, em que sentido ela contribui (ou não) para a (re)configuração pedagógica dos seus processos formativos?

Essa pergunta é pertinente na medida em que ela aponta para as condições internas dos indivíduos, no que diz respeito às suas emoções e sentimentos mobilizadores das suas construções individuais e coletivas. O movimento de reconhecer-se é o de aceitar em si a 
humanidade fundada na presença das emoções e dos sentimentos. Como Dionísio, na Tragédia, não desistiu de si diante das contrariedades do mundo. Ao contrário, ele acreditou na sua divindade e não se deixou envolver por nenhuma forma de poder externo. Ele fez mais, mostrou àqueles que estavam "preparados" o quanto o seu culto era prazeroso e alegre e todos poderiam usufruir dele.

\section{REFERÊNCIAS}

ANASTASIOU, L. G.; ALVES, L. P. (Org.). Processos de ensinagem na universidade: pressupostos para as estratégias do trabalho em aula. Joinvilie, SC: Editora Univille, 2003. $145 \mathrm{p}$.

BEHRENS, M. A. O paradigma da complexidade na formação e no desenvolvimento profissional de professores universitários. Revista Educação, Porto Alegre/RS, ano XXX, n. 3, p. 439-455, set./dez. 2007.

CUNHA, M. I. (Org.). Reflexões e práticas em pedagogia universitária. Campinas: Papirus, 2007a.

CUNHA, M. I. O lugar da formação do professor universitário: Reflexões e Práticas em Pedagogia Universitária. ed. Campinas, SP: Papirus, $2007 \mathrm{~b}$.

DAMÁSIO, A. A estranha ordem das coisas. Portugal: Temas e Debates, 2017.

DAMÁSIO, A. Em busca de Espinosa: prazer e dor na ciência dos sentimentos. Adaptação para o português do Brasil Laura Teixeira Motta. São Paulo: Companhia das Letras, 2004.

ESPINOSA, B. Ética demonstrada à maneira dos geômetras. Trad. Jean Melville. São Paulo: Martin Claret, 2002.

ESPINOSA, B. Tratado da correção do intelecto e do caminho pelo qual melhor se dirige ao verdadeiro conhecimento das coisas. Disponível em:

http://filosofianreapucarana.pbworks.com/f/Tratado+da+Correção+do+Intelecto.pdf. Acesso em: 17 maio 2019.

EURÍPIDES. As bacantes. São Paulo: Hedra, 2010.

FREUD, S. Psicologia das massas e análise do eu: e outros textos. Trad. Paulo César de Souza. São Paulo: Companhia das Letras, 2009.

PIMENTA, S. G. Docência no ensino superior. São Paulo: Cortez, 2005.

PIMENTA, S. G.; ANASTASIOU, L. G. C. Docência no ensino superior. São Paulo: Cortez, 2011.

TARDIF, M. RAYMOND, D. Saberes, Tempo e Aprendizagem do Trabalho no Magistério. Revista Educação \& Sociedade, Campinas, v. 21, n. 73, p. 209-244, 2000. 
TARDIF, M. Saberes docentes e formação profissional. 14. ed. Petropólis, RJ: Vozes, 2012.

\section{Como referenciar este artigo}

SOUZA, S. E. R.; TREVISAN, A. L. A contribuição dos processos formativos na compreensão das dores emocionais de docentes universitários. Revista Ibero-Americana de Estudos em Educação, Araraquara, v. 16, n. 2, p. 524-538, abr./jun. 2021. e-ISSN: 19825587. DOI: https://doi.org/10.21723/riaee.v16i2.13533

Submetido em: 03/04/2020

Revisões requeridas em: 21/07/2020

Aprovado em: 30/10/2020

Publicado em: 01/02/2021 